\title{
Effect of Aerobic Exercises on Functional Capacity in Patients under Hemodialysis
}

\author{
MANAR F. MOHAMMED, M.Sc.*; AMIRA H. DRAZ, Ph.D.**; RANIA N. KARKOUSHA, Ph.D.** and \\ NESRIN G. EL-NAHAS, Ph.D.*** \\ Physical Therapist, Benha University Hospital*, The Departments of Physical Therapy for Basic Science** and \\ Physical Therapy for Cardiovascular/Respiratory Disorders and Geriatrics***, Faculty of Physical Therapy, \\ Benha and Cairo Universities
}

\begin{abstract}
Background: Chronic kidney disease is the progressive deficiency of renal function for months and years, may reach life threatening stage.

Aim of Study: This study was conducted to determine the effect of aerobic exercise versus resisted exercise on urea reduction ratio and 6 minute walk test.

Subjects and Methods: Thirty patients of both sex with chronic renal failure were participated in the study, their age ranged from 25 to 35 years old and recruited from Hemodialysis Unit of benha University Hospital. They were randomly assigned into two equal Groups (A \& B). Group A was received resistance exercise while Group B was received aerobic exercise. Both groups were received session twice per week for 2 months. Measurements were measured twice, before and after treatment: Urea reduction ratio and, 6 minute walk test.

Results: The results showed that there were significant improvement in urea reduction ratio and 6 minute walk test in both groups after treatment while there were no significant difference between two groups after treatment.
\end{abstract}

Conclusion: Both aerobic and resisted training exercise are effective in improvement dialysis efficiency and performance. With no difference between both groups post-treatment.

Key Words: Chronic kidney disease - Aerobic exercise Resisted exercise.

\section{Introduction}

CHRONIC kidney disease CKD affected over 50 million throughout the world, and more than 1 million need dialysis or renal transplantation. The prevalence of CKD increased with increasing incidence of diabetes and hypertension [1]

End stage renal dialysis ESRD results in a negative clinical status, which in turn results in

Correspondence to: Dr. Manar F. Mohammed, Physical Therapist, Benha University Hospital both structural and functional changes in the musculoskeletal system. Consequently, the patient is faced with a sedentary life, making the patient even further dependent. Low functional capacity, exhaustion fatigue and under nutrition was found to be prevalent among incident dialysis patients. Complications such as uremia, anemia, myopathy, and neuropathy decrease muscular strength, cardiopulmonary fitness, and quality of life which is why this population is seen $[2,3]$.

Patients with chronic kidney disease have low levels of physical fitness and function. Their aerobic capacity tends to be only half of that of normal, their strength is low, and they are likely to have problems with mobility and basic activities of daily living. They have an increased incidence of diabetes mellitus, anemia, peripheral vascular disease, hypertension, coronary artery disease, and stroke. Because of electrolyte imbalance and other factors, individuals usually complain of pain, fatigue, and muscle weakness in the spine, hips, knees, and lower extremities [4].

The National Kidney Foundation's Kidney Disease Outcomes Quality Initiative has set the urea reduction ratio (URR) at greater than $65 \%$. So we hypotheses that: Intra dialytic exercise that has increased muscle flow and greater amount of open capillary surface area in working muscle will result in a greater flux of urea and toxins from the tissue to the vascular compartment $[\mathbf{5 , 6 ]}$

Hemodialysis is one of the main renal replacement therapies in patients with ESRD, is a timeconsuming procedure that takes at least 3 to 5 hours a day, two or three times a week. Even though there are many debates about the beneficial effects 
of exercise during hemodialysis (intradialytic exercise) many researchers expect advantages of both dialysis and exercise via intradialytic exercise [7]

Exercise is one of the possible preventive maneuvers to reduce muscle protein loss and maintain muscle function. Recently, many studies have shown the importance of exercise or regular physical activity to prevent muscle wasting in CKD patients.

Physical exercise has beneficial effects on functional capacity, quality of life, cardiovascular risk factors, anemia, serum lipid levels, endothelial function, inflammation, type 2 diabetes mellitus and psychosocial problems in CKD patients [8]

Resistance exercise and aerobic exercise induce muscular contraction, which may increase strength, and the size of skeletal muscles [9].

A review article, based on 29 trials shows that exercise training in dialysis patients improves haemoglobin levels and urea. Another study show that exercise prescription in patients with CKD includes resistive exercise results in increase haemoglobin level and urea [10].

There is gap in litratures concerning the effect of resistance versus aerobic exercise on hemodialysis efficiency and physical performance in renal failure patients. So this study was conducted to examine the effect of resisted exercise versus aerobic exercise on dialysis efficiency and physical performance.

\section{Subjects and Methods}

Design pre and post 2 groups experimental design. (Dependent, aerobic and resisted exercises, independent urea reduction ratio and 6 minuteswalk test). Measurements taken twice.

\section{Sample:}

This study was conducted in Hemodialysis Unit of Benha University Hospital and all cites around. April 2018 to December 2018. Thirty patients of both gender had been participated in the study and was recruited from Hemodialysis Unit. Each participant signed the consent form. The study was approved by the Institutional Ethical Committee of Faculty of Physical Therapy, Cairo University with code number P.T.REC/012/001933. Patients were randomly divided into two equal groups numbers using computerized random sequence generator method.

Group A (resisted exercise): It composed of 15 patients who received resisted exercise.
Group B (aerobic exercise): It composed of 15 who received aerobic exercise.

Inclusive criteria: Subjects with the following criteria would be enrolled in this study:

1- Age ranged between 25-35.

2- All patients with stage 4 of chronic renal failure.

3- All patient were stable on dialysis for 2 months.

4- All patients were free from lower extremity graft.

5- Patient did not take exercise in 6 months before treatment.

6- Blood pressure under medical control.

7- Stable blood sugar.

Exclusive criteria: Patients would be excluded from the study if they have:

1- Active infection, inflammation, autoimmune disorder and malignancy.

2- Sever muscle weakness or skeletal problem.

3- History of repeated hypoglycemia.

4- Cardiopulmonary complication to resistive exercise.

5- Cerebrovascular accident within 6 months before treatment.

6- History of prior exercise training.

7- Hospitalization during prior month.

\section{Instrumentation:}

Evaluation of functional performance using 6minute walk test (6 MWT).

The six minutes' walk test (6 MWT) performed indoors, along a long, flat, straight, enclosed corridor with a hard surface that is seldom traveled. The length of the corridor marked at starting line and end line marked on the floor using brightly colored tape. Ask the patient to walk as far as possible without jogging or running, the patient performs the test at his own rate [11].

\section{3- Laboratory investigation:}

$$
\mathrm{URR}=\frac{\begin{array}{c}
\text { Predialysis blood urea nitrogen (BUN) } \\
- \text { post dialysis Bun }
\end{array}}{\text { Predialysis BUN }} \times 100
$$

\section{Treatment procedure:}

Group B: Using stationary bicycle for aerobic exercise two times per week for 2 months during hemodialysis for the first 2 hours. 
Group A: Resistance exercise using ankle weight for knee extension and flexion. For 30min. for two times per week with in 8 weeks.

The program of treatment of resisted exercise consist of three parts:

First part: Warming up (approximately 5 minutes) is in the form of free passive stretching for lower limb.

Second part: The main part (10 to 30 minutes) is moderate resistance exercise of lower extremities using ankle weights for knee extension and flexion and hip abduction and flexion. Intensity of exercise: $60 \%$ of $1 \mathrm{RM}$.

Sets: 2-3 sets with two to three minutes of rest between sets to allow recovery. Repetions: 8-15 reps. Weight: Increase by $0.5 / 1 \mathrm{~kg}$. Session frequency: 2 times per week. Starting weights were determined from a three repition ( $3 \mathrm{RM}$ ) maximum using ankle weights, a3RM is the maximum weight that can be lifted three times with proper technique .training started when the 3 sets were tolerated and the weight increased by $0.5 / 1 \mathrm{k}$. Blood pressure and heart rate were monitoring frequently during the session.

Third part: Cooling down (approximately 5 minutes) are passive exercise and stretching of lower limb and breathing exercise [12,13]

The patients were taught to stop the exercise and notify if they felt any dizziness, headache, palpitations, nausea, anxiety, exhaustion or any other adverse effects.
Group B: Using stationary bicycle for aerobic exercise two times per week for 2 months during hemodialysis for the first 2 hours.

The program of treatment consist of 3 parts:

First part: Warm-up (approximately 5 minutes) in form of free active exercises for lower extremities in the supine position.

Second part: The main part (10 to 30 minutes) exercise on a stationary bicycle. Intensity: $60 \%$ of MHR. Frequency: 2 times per week.

Third part: Cool-down (approximately 5 minutes) in form of free active exercises for lower extremities in the supine position and breathing exercises [14].

Analysis and statistical design:

Descriptive statistics: The mean and standard deviation of each group were calculated for each variable.

Inferential statistics:

Collected data in this study were analyzed by using MANOVA to analyze data and comparing results.

\section{Results}

\section{1- Demographics:}

Group A: 15 patients received resistance exercise, their mean age was $(31.27 \pm 3.43)$ years. Group B: 15 patients received aerobic exercise, as shown in (Table 1$)$; their mean age was $(31 \pm 3.25)$ years. Independent $t$-test showed that there was no significant difference between two groups in their age.

Table (1): MANOVA test for pre and post study mean values of blood urea and 6 MWT for both groups.

\begin{tabular}{|c|c|c|c|c|c|}
\hline Item & $\begin{array}{c}\text { Pre-treatment } \\
\text { Mean } \pm \text { SD }\end{array}$ & $\begin{array}{l}\text { Post-treatment } \\
\text { Mean } \pm \text { SD }\end{array}$ & $\begin{array}{c}\% \text { of } \\
\text { improvement }\end{array}$ & $\begin{array}{c}p- \\
\text { value }\end{array}$ & Sig. \\
\hline \multicolumn{6}{|c|}{ Blood Urea $(\mathrm{mg} / \mathrm{dL})$ : } \\
\hline Group A & $117.07 \pm 26.8$ & $89.47 \pm 24.18$ & $23.57 \%$ & 0.004 & NS \\
\hline Group B & $111.6 \pm 25.5$ & $86.8 \pm 22.69$ & $22.22 \%$ & 0.008 & \\
\hline$p$-value & 0.549 & 0.770 & & & \\
\hline \multicolumn{6}{|l|}{$6 M W T(m):$} \\
\hline Group A & $293.67 \pm 32.5$ & $340.33 \pm 55.8$ & $15.88 \%$ & 0.004 & NS \\
\hline Group B & $292.27 \pm 37.8$ & $341.53 \pm 40.8$ & $16.85 \%$ & 0.003 & \\
\hline$p$-value & 0.929 & 0.939 & & & \\
\hline
\end{tabular}

Pre study means values within both groups:

\section{A- Blood urea:}

Table (1) showed that as demonstrated, MANOVA test was used to analyze blood urea ( $\mathrm{mg} / \mathrm{dL})$, the mean values and SD of blood urea for subjects in Groups (A and B) before the study were (117.07 \pm $26.8)$ and $(111.6 \pm 25.5) \mathrm{mg} / \mathrm{dL}$ respectively. There were no significant differences between two groups in their mean values of blood urea pre-study $(p>0.05)$. 


\section{6 minute walk test:}

Table (1) showed that as demonstrated, MANOVA test was used to analyze distance measured by 6 MWT $(\mathrm{m})$, the mean values and SD of distance measured by 6 MWT for subjects in Groups (A and $\mathrm{B}$ ) before the study were $(293.67 \pm 32.5)$ and $(292.27 \pm 37.8) \mathrm{m}$ respectively. There were no significant differences between two groups in their mean values of distance measured by 6 MWT prestudy $(p>0.05)$.

\section{Comparison of URR between the two groups:}

As shown in (Table 2) and demonstrated, the mean values $\pm \mathrm{SD}$ of URR of Groups $\mathrm{A}$ and $\mathrm{B}$ were $(23.5 \pm 11.2)$ and $(22.3 \pm 12.1)$ respectively. There was no significant difference $(p>0.05)$.

Table (2): Mean values of URR of subjects in both groups.

\begin{tabular}{ll}
\hline URR & Mean \pm SD \\
\hline Group A & $23.5 \pm 11.2$ \\
Group B & $22.3 \pm 12.1$ \\
$t$-value & 0.286 \\
$p$-value & 0.777 \\
Sig. & $\mathrm{NS}$ \\
\hline
\end{tabular}

\section{Discussion}

This study was conducted to determine the effect of aerobic exercise versus resisted exercise on urea reduction ratio and 6 minute walk test. The study showed statistical significant improvement in urea reduction ratio and 6 minute walk test in both groups post-treatment (Group A that received resisted exercise and Group B that received aerobic exercise) while there were no statistical significant difference in urea reduction ratio and 6 minute walk test between both group posttreatment.

The finding of the present study showed decrease of urea level pre and post-treatment so improvement of urea reduction ratio occur while there was anon significant difference post-treatment between Group A and Group B ( $p>0.05)$.

Improvement of urea was due to improvement of clearance of uremic toxins was most probably caused by increase blood flow in loaded muscle and increase displacement of toxic substance to plasma.

The finding of the present study showed a significant improvement of 6 minute walk test pre and post-treatment in both groups of the study while there was a non-significant difference posttreatment between Group A and Group B ( $p>0.05)$.
It had been suggested that exercises improved removal of uremic toxins into vascular compartments during dialysis. Muscular blood flow increased the efflux of urea and cellular permeability to water soluble molecules as creatinine due to exercises induced higher body temperature so reduce muscle protein loss and maintain muscle function.

Regarding to urea reduction ratio the results of this study agreed with that of Jiang et al., 2018 reported that a total of 27 RCTs involving 1215 subjects were analyzed. Compared with no exercise, intra dialytic exercise (aerobic or resisted) increased dialysis adequacy (Kt/V) (MD 0.07, 95\% CI 0.01 to $0.12, p=0.02$ ) and maximum volume of oxygen that the body can use during physical exertion peak oxygen consumption (MD 4.11, 95\%CI 2.94 to 5.27, $p<0.0001$ ), alleviated depression standardized mean difference $(-1.16,95 \% \mathrm{CI}-1.86$ to -0.45 , $p=0.001)$ and improved physical component summary-short form-36 (SF-36) level (MD 7.72, 95\% CI 1.93 to $13.51, p=0.009)$.

SO intradialytic exercise resulted in benefits in terms of improving haemodialysis adequacy, exercise capacity, depression and quality of life for haemodialysis.

Giannaki et al., [15] reported that all efficiency indices significantly improved in the prolonged intradialytic exercise $\mathrm{Kt} / \mathrm{V}$, urea reduction ratio, and creatinine reduction ration significantly improved by $20 \%, 11 \%$, and $26 \%$, respectively, while potassium plasma levels were reduced by $77.5 \%$ $(p<0.05)$. In conclusion prolonged low-intensity intradialytic exercise improved HD efficiency, with no adverse effects. HD patients should be encouraged to participate in exercise regimes not only for the known long-term benefits regarding their cardiovascular health but also for the acute effect of exercise in the HD adequacy.

Mohseni et al., [16] evaluates the effect of 8weeks intradialytic exercise program (consisting of 15 minutes low-intensity exercise during the first 2 hours of dialysis) on dialysis efficacy, in an open randomized controlled trial, a total of 50 clinically stable hemodialysis patients were enrolled into the study and randomly allocated into two groups: The aerobic exercise group $(n=25)$ and the control group $(\mathrm{n}=25)$. Aerobic exercises were done in the intervention group for $15 \mathrm{~min} /$ day, three times a week for 2 months. The dialysis efficacy was assessed prior to and at the end of each month of the program results of this study revealed that the efficacy of dialysis increased at the end of the first 
month and remained elevated for the duration of the program in the exercise program has increased the efficacy of dialysis and may be considered as a safe, complementary and effective modality for hemodialysis patients.

Parsons et al., [17] reported that a 5-month intradialytic exercise program in which subjects exercised 3 times a week (cycle ergometer, ministepper) for 30 minutes in each of the first 2 hours of HD. The dialysis adequate parameter SPKt/V increased $11 \%$ at the end of the first month of the program $(p<.05)$ and remained elevated for the duration of the program (18\%-19\%). Distance walked on the 6 MWT increased by $14 \%$ at both weeks 10 and $20(p<.05)$.

Parsons et al., [18] reported that self-care hemodialysis patients performed cycle ergometry exercise 3 times per week during their dialysis session for 15min during each of the first 3 hours of dialysis. Exercise during dialysis enhanced Dialysate Urea Clearance (DUC) but not serum urea clearance $(\mathrm{Kt} / \mathrm{V})$. Alterations in the modality and the timing of exercise during dialysis may be required to elicit increase in scrum urea clearance. It is also recommended that exercise during the first 2 hours of dialysis.

Sun et al., [19] studied the effect of aerobic exercises on 10 patients served as controls while 10 exercised throughout the dialysis session with 5 to 10 minutes of rest when necessary, using an adapted cycle ergometer, single and equilibrated pool (on-line dialysate monitor) Kt/V were significantly enhanced (25\%), URR increased (10\%) and urea rebound was reduced in the exercising as compared with control patients, in the face of a constant protein catabolic rate.

Van Vilsteren et al., [20] conducted a study to determine whether a low-to-moderate intensity pre-conditioning exercise counseling could improve behavioral change, physical fitness, physiological condition and health-related quality of life in ninetysix haemodialysis patient were randomized into an exercise groups $(n=35)$ and a control group $(n=43)$ demonstrates that participation in a lowto-moderate intensity exercise program linked with exercise counselling yields a significant increase in behavioral change, reaction time, lower extremity muscle strength, $\mathrm{Kt} / \mathrm{V}$ and three components of quality of life, and no significant effect in the control group, participating in low-to-moderate intensity pre-conditioning exercise program showed beneficial effect on behavioral change, physical fitness, physiological conditions and health-related quality of life.
Zaluska et al., [21] studied the effect of aerobic exercise in $10 \mathrm{HD}$ patients who cycled for 30 minutes during the first hours of dialysis overa period of 6 months, noted a $16.5 \%$ improvement in $\mathrm{spKt} / \mathrm{V}(1.03 \pm 0.27$ to $1.20 \pm 0.28, p=.026)$. Some of this improvements $\mathrm{m}$ however may have been associated with a concurrent increase in protein catabolic rate because increased urea production will increase urea clearance.

Also the results of this study were in agreement with my result in physical performance in the aerobic exercise training group (Group A) that agreement with:

The ability patients were included in a protocol with intradialytic aerobic training on a cycle ergometer. The exercise was conducted during the first hour of the HD session, 30 minutes, three times a week for four months. The results showed an improvement in functional capacity $(p=0.02)$ and cognitive function $(p=0.01)$.

Chojak et al., [14] reported that after the sixmonths of exercise program, the exercise was performed during the hemodialysis treatment on a stationary bicycle three times per week the patients showed; a significant increase in the number of repetitions performed in sit-to-stand-to-sit test after 3 months as compared to baseline (from 23.46 to 31.67 ) and an increased after 6 months of exercise program (from 23.46 to 36.50 ) and concluded that exercise training during the hemodialysis treatment using stationary bicycle is technically feasible and safe for the screened patients and may increase exercise capacity and leg muscles strength. Physical exercise therapy should constitute an important part of treatment of patients undergoing hemodialysis.

Headley et al., [23] reported a 5\% increase in distance walked on the 6 MWT $(522 \pm 49 \mathrm{~m}$ to $546 \pm$ $54 \mathrm{~m}, p=.05$ ) after 12 weeks of off-dialysis resistance training.

Henrique et al., [23] evaluated the effect of aerobic exercise during hemodialysis on the physical capacity and blood pressure of patients with chronic rental failure, 14 patients with chronic kidney disease under hemodialysis, before and after 12 weeks of aerobic exercise performed during hemodialysis session. Patients underwent ambulatory blood pressure monitoring for 24 hours, 6minute walk test and cardiopulmonary exercise test before and after the exercise period.

Knap et al., [25] reported that individual regular exercise is an important part of rehabilitation of 
patients on renal replacement therapy. The influence of it on physical exercise capacity, endurance, muscle strength and social and emotional status is very high. The diminishing of cardiovascular risk factors is expected. Side effects of exercise are very rare. Also exercise in the first hour of hemodialysis could be an option for better rehabilitation, aerobic and resistance exercise are also important for the anabolic effect and diminishing of malnutrition patients with ESRD.

Painter et al., [25] found an $8 \%$ increase in the distance walked on the 6 MWT in 44 patients who participated in an 8 week home program and an 8 week intradialytic exercise program as compared to their baseline distance of $517 \pm 190 \mathrm{~m}$.

Reboredo et al., 2010 reported that aerobic exercise training performed during HD sessions for 12 weeks increased physical functioning reduced blood pressure levels, and contributed to the control of anemia and quality of life in patients with ESRD.

Yousry et al., [35] reported that exercise training in ESRD patients is effective in improving physical functioning, family and social interactions and reducing depression. It can lead to a better quality of life and increases the physical working capacity of HD patients.

Young et al., [36] evaluated 16 patients who underwent $1 \mathrm{~h}$ of exercise a day for 12 weeks, eleven of those patients who were undergoing chronic HD showed a significant improvement in arterial stiffness. Which was interpreted as being due to a better supply/demand myocardial balance with improved mechanical stress of the large arteries.

Kouidi et al., [37] stated that the most severely depressed patients had the greatest beneficial effect from exercise training, in parallel to significant improvements in quality of life parameters.

Gravelle et al., [38] found that patients who performed RE showed improvements in physical and psychological fitness, improving QOL. In patients with CKD, and those who exercise while understanding HD showed improvement in their uremic conditions.

In other studies as $[\mathbf{2 5 , 2 6}]$ exercise programs improved anxiety symptoms as well as the physical and mental health scores of the SF-36 quality of life scale.

Cheema et al., [27] reported that in dialysis patients, both aerobic exercise and resistance ex- ercise have demonstrable effects. A comprehensive tabulation of such studies, including the type of exercise, the timing relative to the dialysis session and the resulting effect on physiological function has been published.

Knap et al., [24] reported that regular exercise is an important part of rehabilitation of patients on renal replacement therapy. The influence of it on physical exercise capacity, endurance, muscle strength, and social and emotional status is very high. The diminishing of cardiovascular risk factor is expected. Side effects of exercise are very rare. Also exercise in first hour of hemodialysis can be an option for better rehabilitation. Aerobic and resistance exercise are also important for the anabolic effect and malnutrition in patient with ESRD.

Kopple et al., [28] examined the effects of different exercise training (strength, endurance and combination of both) in RNA levels in muscle genes. It was observed that exercise training in hemodialysis patients increased $m$ RNA changes in skeleton muscle and muscle Insulin-like Growth Factor-1 (IGF-1) protein. This factor is important as it accelerate protein anabolism.

Koh et al., [29] reported that patients undergoing 12 weeks of intradialytic training statistically significant improvements in muscle strength of the quadriceps and biceps were observed, improving physical function and vitality and the QOL domains.

Leehey et al., [30] studied the effect of exercise for 24 weeks on medical treatment in patients with CKD. These patients performed exercise 3 times a week. The exercise training resulted in an increase in physical and functional capacity of the patients, accompaniment by a slight but insignificant decrease in systolic blood pressure at rest, and increased muscle strength as assessed by static and dynamic resistance.

Balakrishan et al., [31] analyzed the effect of resistance exercise on muscle mass and strength in chronic kidney disease stage 3 and 4 patients with low protein diet for 12 weeks. Participants exercised three times per week under supervision. In conclusion it was found that oxidative metabolic capacity improved in uremic skeleton muscle.

Chen et al., [32] randomized 50 patients with a mean age of $(69 \pm 13)$ years on long term dialysis and classified the patients into low intensity strengthening exercise and stretching exercises for control group. The study aimed to evaluate physical performance, twice weekly during the second hour of hemodialysis for a total of 48 exercise sessions. 
Sessions started with a 5-min warm-up and ended with a 5-min cool-down. Exercises were for lower body only using ankle weights progressively in half-pound increments from 0.5 to $2 \mathrm{~kg}$. As a result progressive low intensity strengthening training was found to be an effective and safe approach in maintenance of hemodialysis patients. It is understood from this study that intradialytic low intensity strengthening training might reverse functional losses, which are also known as physical inadequacy and disability of hemodialysis patients and might protect their acquisitions.

Ronaldo et al., [13] stated that the RE program of low intensity, $40 \%$ of the maximum resistance, facilitated realization. For example, a 51-year-old man, started training with a $500 \mathrm{~g}$ ankle weight on each leg, which is a reduced load for healthy men 50 years of age. He gradually gained fitness and muscle strength with exercise and could train with a $2 \mathrm{~kg}$ ankle weight at the end of 8 weeks, a fact that surprised the patients raising his self-esteem, enabling him to participate in activities that had been limited after starting hemodialysis.

Finding of study proved that resistance exercise training is a useful modality that improve hemodialysis efficiency; resistance exercise group showed a statistical significant increase in the urea reduction ration in the study group post-treatment compared with pretreatment $(p=0.01)$ with the mean difference between both groups was 13.28.

There was a statistical significant increase in all aspects of QOL showed in Medical Outcomes Study Questionnaire Short Form 36 Health Survey (SF-36); Physical Functioning (PF), role of limitation due to physical health (RP), role of limitation due to emotional problems (RE), Vitality (VIT), Emotional Wellbeing (EW), Social Functioning (SF), Bodily Pain (BP) and General Health (GH) with percentages of improvement were $37.17 \%$, $40.36 \%, 75.06 \%, 34.46 \%, 43.94 \%$, $46.55 \%$, $32.57 \%, 18.83 \%$ respectively more than pretreatment.

Samah and haidy, [33] found that significant decrease in the level of CRP $(\mathrm{mg} / \mathrm{L})$ and creatinine level $(\mathrm{mg} / \mathrm{dL})$, increase in the albumin $(\mathrm{g} / \mathrm{dL})$ and a significant improvement in the results of Sit-tostand-to sit test and 6 MWT between pre-treatment and post-treatment in both groups of the study ( $p$ $<0.05)$. While there was a non-significant difference post-treatment between Group A and Group B $(p>0.05)$. Finally, there were no differences between the effects of resisted exercises or aerobic exercises in patients with chronic kidney disease.
The results of aerobic exercise study contradict with:

Afshar et al., [12] found that aerobic and resistance exercises that conducted to hemodialysis patients were significantly correlated with a reduction of serum creatinine and CRP levels, thus aerobic exercise induced more reduction, however the exercise had no influence on weight, $\mathrm{Kt} / \mathrm{V}$ values, serum urea, albumin, hemoglobin or lipid levels.

Vaithilingham et al., [34] reported that no changes in equilibrated $\mathrm{Kt} / \mathrm{v}$ (on line urea monitor) or URR (71 .9-9. 1 to 73.9-7.6) were found in $12 \mathrm{HD}$ patients who use cycle exercise on average of 69$16 \mathrm{~min} /$ wk. or about $13 \mathrm{~min} /$ dialysis sessions.

Riahi et al., 2012 evaluated the effects of aerobic exercise during hemodialysis on the efficacy of dialysis, muscle atrophy and physical performance in patients with chronic renal failure on $30 \mathrm{HD}$ patients for 20 weeks during the first two hours of their hemodialysis on stationary bicycle, three times per week, for $60 \mathrm{~min}$ each time and reported increase in the distance walked during the 2 MWT and a significant improvement in atrophy in exercise group $(p<0.05)$. No significant differences were observed in efficacy of dialysis after exercise program $(p>0.05)$ and concluded that regular exercise has a significant impact on physical performance and muscle atrophy in hemodialysis patients and can be used as part of treatment for hemodialysis patients, but no significant effect has on efficacy of dialysis after exercise program.

The results of Afshar et al., [12] and Ronaldo et al., [13] studies unsupported the effect of resisted exercise study on dialysis adequacy:

Afshar et al., [12] found that aerobic exercise and resisted exercises that conducted to hemodialysis patient were significantly correlated with a reduction of serum creatinine and CRP levels, thus aerobic exercise induced more reduction, however the exercise had no influence on weight, $\mathrm{Kt} / \mathrm{V}$ values, serum urea, albumin, and hemoglobin or lipid levels.

Ronaldo et al., [13] found that the protocol of 8 weeks of RE during HD resulted in significant, although slight, alterations in biochemical parameters. However, they showed no clinically important impact on dialysis.

\section{Limitations:}

Limitation of this study were:

Psychological conditions of the patients that might affect the evaluation and treatment proce- 
dures. Refusal of few female patients to participate in study group due to lack of enough place for gender separation.

\section{Conclusion:}

Both aerobic and resisted training exercise are effective in improvement dialysis efficiency and performance.

\section{References}

1- ZANG Q. and ROTHENBACHER D.: Prevalence of chronic Kidney disease in population-based studies: Systematic review. BMC public Health, 8: 117-37, 2008.

2- OVEREND T., ANDERSON C., ANURADHA S., PERRYMAN B. and LOCKING-CUSOLITO H.: Relative and absolute reliability of phsycial and absolute reliability of physical function measures in people with ESRD. Physiother Can., 62 (2): 122-8, 2012.

3- TUTTLE D. and KRAMER H.: Cancomprehensive lifestyle change alter the course of chronic kidney disease?, Semin. Nephrol., 29 (5): 512-23, 2009.

4- MAKHLOUGH A., ILALI E., MOHSEN R. and SHAHMOHAMMADI S.: Effect of intradialytic aerobic exercise on serum electrolytes levels in hemodialysis patients. Iranian Journal of kidney disease, Vol. 6, No. 2, pp. 11923, 2012.

5- KONG C., TATTERSALL J., GREENWOOK R. and FARRINGTION K.: The effect of exercise during haemodialysis on solute removal. Nephrol Di Transplant., 14 (12): 2927-31, 1999.

6- SUN Y., CHEN B., JIA Q. and WANG J.: The effect of exercise during hemodialysis on adequacy of dialysis. Zhonghua Neikezazhi, 41 (2): 79-81, 2002.

7- TAWNEY K.W., TAWNEY P.J. and KVOACH J.: Dicplacement and rehabilitation in end-stage renal sisease. Semin Dials, Vol. 16: 447-52, 2003.

8- DAUL A.E., SCHAFERS R.F., DAUL K. and PHILIPP T.: Exercise during hemodialysis. Clin. Nephrol., 61 (Suppl 1): S26-30, 2004.

9- GIANOLA S., PECORARO V. and LAMBIASE S.: Efficacy of muscle exercise in patients with muscular dystrophy; A systematic review showing a missed opportunity to improve outcomes. Plos One, 8 (6) Article ID 65414, 2013.

10- HEIWE S., EKHOLM A. and FEHRMAN-EKHOLM I.: The Importance of Exercise Programs in Haemodialysis Patients, Progress in Hemodialysis-From Emergent Biotechnology to Clinical Practice, Prof. Angelo Carpi (Ed.), ISBN: 978-953-307-377-4, 2011.

11-HOLUB C., LAMONT M., LOMBARDO A., PENCE T., SCHULTZ G. and TEPPER S.: The reliability of the sixminute walk test in patients with end-stage renal disease. Acute Care Perspect, 11 (1): 8-11, 2002.

12- AFSHAR R., SHEGARFY L., SHAVANDI N. and SANAVI S.: Effects of aerobic exercise and resistance training on lipid profiles and inflammation status in patients on maintenance hemodialysis. Indian J. Nephrol., 20: 185-9, 2010.
13- RONALDO R., GUSTAVO L., ANDERSON L., ANA M., JOSE A., DENISE P. and NESTOR S.: Effect of resistance exercise interadialytic in renal patients chronic in hemodialysis. Brass Nephrol., Vol. 35, No. 1: 13-9, 2013.

14- CHOJAK K., SMOLENSKI O., MILKOWSKI A. and PITROWSKI W.: The effects of 6-month physical training conducted during hemodialysis in ESRD patients. Med. Rehabil., 10 (2): 25-41, 2006.

15- GIANNAKI C.D., STEFANIDIS I., KARATZAFERI C., LIAKOS N., ROKA V., NTENTE I. and SAKKAS G.K.: The effect of prolonged intradialytic Exercise in hemodialysis efficiency Indices ASAIO. Journal:Amercian Society of Artificial internal organs May/June 2011-Volume 57 Issue 3-PP213-218, 2011.

16- MOHSENI R., EMAMI ZEYDI A., ILALI E., ADIB HAJBAGHERY M. and MAKHLOUGH A.: The effct of intradialytic aerobic exerciseon dialysis efficacy in hemodialysis patients; a randomized controlled trial. Oman Med. J., 2013 Sept., 28 (5): 345-9, 2013.

17- PARSONS T.L., TOFFELMIRE E.B., KING-VAN and VLACK C.E.: Exercise training during hemodialysis improves dialysis efficacy and physical performance. Arch. Phys. Med. Rehabil., 87: 680-7, 2006.

18- PARSONS T.L., TOFFELMIRE E.B. and KING C.E.: The effect of an exercise program during hemodialysis on dialysis efficacy, bood pressure, and quality of life in end-stage renal disease patients. Clin. Nephrol., 61: 26174, 2004.

19- SUN Y., CHEN B., JIA Q. and WANG J.: The effect of exercise during hemodialysis on adequacy of dialysis. zhonghua Neikezazhi, 41 (2): 79-81, 2002.

20- VAN VILSTEREN M., GREEF M. and HUISMAN R.: The effects of alow-to-moderate intensity pre-conditioning exercise programme linked with exercise counseling for sedentary hemodialysis patients in the Netherlands; results of a randomized clinical trial. Nephrol. Dial. Transplant. 20: 141-6, 2005.

21- ZALUSKA A., ZALUSKA W.T., BEDNAREKSKUBLEWSKA A. and KSIAZEK A.: Nutrition and hydration status improve with exercise training using stationary cycling during hemodialysis (Hd) in patients with end stage renal disease (ESRD). Ann. Univ. Mariae Curie Sklodowska, 57: 342-6, 2002.

22- HEADLEY S., GERMAIN M., MAILLOUX P., MULHERN J., ASHWORTH B., BURRIS J. and JONES M.: Resistance training improves strength and functional measures in patients with end-stage renal disease. American Journal of Kidney Diseases, 40 (2): 355-64, 2002.

23- HENRIQUE D., REBOREDO M., FARIA R., CHAOUBAH A., BASTOS M. and De PAULA R.: Exercise Training During hemodialysis Reduces Blood Pressure and increases Physical Fucntioning and Quality of life. Artificial Organs, 34: 586-93, 2010.

24- KNAP B., PONIKVAR J., PONIKVAR R. and BREN A.: Regular exercise as a part of treatment for patients with End-stage Renal Disease Therapeutic Apheresis and Dialysis, Vol. 9 No. 3: 211-3, 2005.

25- PAINTER P., CARLSON L.,CAREY S., PAUL S. and MYLL J.: Physical functioning and health related quality 
of life changes with exercise training in hemodialysis patients. Am. J. Kidney Dis., Vol 35: 82-492, 2000.

26- OH-PARK M., FAST A. and GOPALS: Exercise for the dialyzed aerobic and strength training during hemodialysis. AM. J. Phys. Med. Rehabil., Vol. 81: 814-21, 2002.

27- CHEEMA B.S. and FIATARONE SINGH M.A.: Exercise training in patients receiving maintenance hemodialysis: A systematic review of clinical trials. Am. J. Nephrol., Vol. 25: 325-64, 2005.

28- KOPPLE J.D., WANG H., CASABURI R., FOURNIER M., LEWIS M.I., TAYLOR W. and STORER T.W.: Exercise in maintenance hemodialysis patients induces transcriptional changes in goes favoring anabolic muscle J. Am. Soc. Nephrole, Vol. 18: 2975-86, 2007.

29- KOH K.B., FASSETT R.G., SHARMAN J.E., COOMBES J.S. and WILLIAMS A.D.: Intradialytic versus homebased exercise training in hemodialysis patients: A randomized Controlled trial. BMC Nephrol., Vol. 10: 1-6, 2009.

30- LEEHEY D.J., MOINUDDIN I., BAST J.B., QURESHI S., JELINEK C.S. and COOPER C.: Aerobic exercises in obese diabetic patients with chronic kidney disease: A reandomized and controlled pilot study, Cardiovase diabetol 8-62, 2009.

31- BALAKRISHAN V.S., RAO M., MENON V., GORDON P.L., PILICHOWSKA M., CASTENADA F. and CASTENADA-SCEPPA C.: Resistance training increase muscle mitchrondrial biogenesis in patients with chronic kidney disease. Clin. J. Am. Soc. Nephrol., Vol. 5, No. 6: 996 $1002,2010$.

32- CHEN J.L., GODFREY S., NG T.T., MOORTHI R., LIANGOS O., RUTHAZER R., JABER B.L., LEVERY A.S. and CASTENDA-SCEPPA C.: Effect of intradialytic, low intensity strength training on functional capacity in adult hemodialysis patients: A randomized pilot trail. Nephrolgy dialysis transplant, Vol. 25, No. 6 1936-43, 2010.

33- SAMAH H. NAGUIB and HAIDY N. ASHEM: Resisted Exercises versus Aerobic Exercises in Patients with chronic kidney disease, Vol. 10 (4): 573-81, 2017.

34- VAITHILINGHAM I., POLKINGHORNE K.R., ATKINS R.C. and KERR P.G.: Time and exercise improve phosphate removal in hemodialysis patients. Am. J. Kidney Dis., 43 (1): 85-9, 2004.

35- YOUSRY M., ZEIDN M., WAGDY E., EL SWEFY M. and SALAH E.: Assessment of physical performance and quality of life before and after correction of anemia and malnutrition in hemodialysis patients. J.M.R.I., Vol. 26 no. 4: 298-306, 2005.

36- YOUNG J.C.: Exercise prescription for individuals with metabolic disorders. Pratical considerations, Sports Med., Vol. 19: 43-54, 1995

37- GRAVELLE B.L. and BLESSING D.L.: Physiological adaptations in women concurrently training for strength and endurance. J. Strenght. Cond. Res., Vol. 14: 5-13, 2000 .

\section{تآثير الآنواع الهختلفة من التهارين الهوائية على القدرات الوظيفية

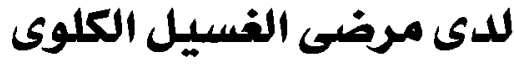

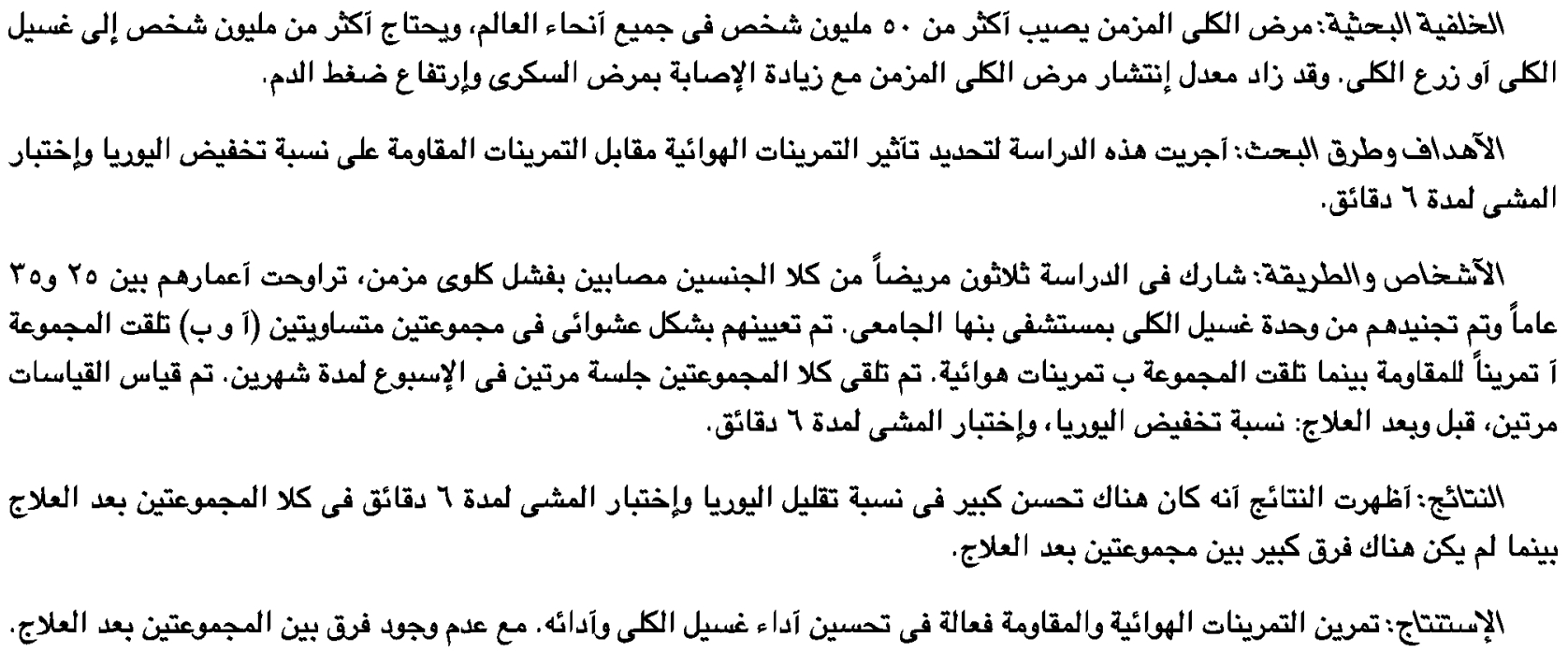

